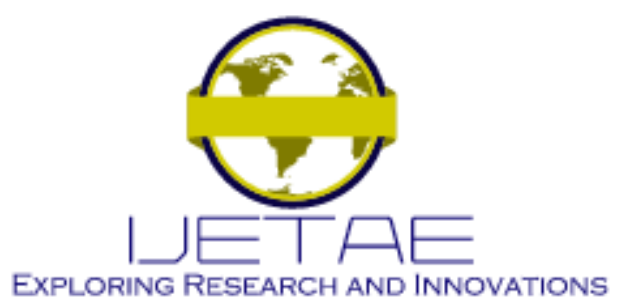

International Journal of Emerging Technology and Advanced Engineering

Website: www.ijetae.com (E-ISSN 2250-2459, Scopus Indexed, ISO 9001:2008 Certified Journal, Volume 11, Issue 10, October 2021)

Manuscript Received: 03 September 2021, Received in Revised form: 08 October 2021, Accepted: 14 October 2021

DOI: 10.46338/ijetae1021_07

\title{
Analysis of Systems Thinking Safety by Artificial Intelligence (AI) Algorithm in South Korean Nuclear Power Plants (NPPs)
}

\author{
Chang Hyun Baek ${ }^{1}$, Kyung Bae Jang ${ }^{2}$, Tae Ho Woo ${ }^{3}$ \\ ${ }^{1,2,3}$ Department of Mechanical and Control Engineering, The Cyber University of Korea, 106 Bukchon-ro, Jongno-gu, \\ Seoul 03051, Republic of Korea
}

\begin{abstract}
The artificial intelligence (AI) is applied to the safety analysis in the South Korean nuclear power plants (NPPs). The reinforcement learning (RL) is one of promising skills in the wise manipulations for the nuclear safety analysis where the reward is a critical factor to make the modelling. In the simulations, $Y$-axis means the relative value which shows the quantity of the accident possibility. The highest value is 4.0 in $46.25^{\text {th }}$ year in which the values are increasing gradually. Otherwise, the values in the case with Agent gradually decrease. The highest value is near initial stage, which means the operation in NPPs is comparatively unstable. In the result, the values in the AI based controller graphs are higher than those of the other one. The RL algorithm is expressed by the Agent in this modelling, which is the most important factor in the AI-based operation in NPPs.
\end{abstract}

Keywords-Safety, Artificial intelligence, Reinforcement learning, Systems thinking, Vensim

\section{INTRODUCTION}

The artificial intelligence (AI) is applied to the safety analysis in the nuclear power plants (NPPs) in South Korea. The reinforcement learning (RL) is one of promising skills in the wise manipulations for the nuclear safety analysis where the reward is a critical factor to make the modeling. Figure 1 shows the typical feature of NPPs in South Korea where the multiple protection systems are installed for the radioactive material leak from the reactor. From nuclear fuel to containment building, several kinds of covering systems are seen. Figure 2 shows the algorithm of the RL in the general logic of the AI-based configuration [1]. Machine could be trained by the repeated calculations in the designed scenarios, especially for the nuclear accident which is one of very complicated procedures. Considering past three severe accidents of NPPs, the emergency safety systems were not operated effectively and even went to extremely uncontrollable states in the Chernobyl and Fukushima cases. So, it is reasonable to seek the much more highly reliable method to manage the possible nuclear accident.
In the operations of the NPPs, the general safety concept had experienced several failures as follows,

- The dependence-in-depth: It is a major concept in the nuclear safety where the multiple barrier is equipped to control the nuclear fuel failures. So, the Chernobyl nuclear accident is a model of the multiple barrier effectiveness in which if the last multiple barrier, the massive containment building, were constructed, the hazard radioactive material could not disperse to the environment. However, this statement would be doubtful due to the recent Fukushima nuclear disaster where the confined hydrogen gas exploded and subsequently the reactor core facility also collapsed.

- The multiple barrier: This has been regarded as the very well made design. Although the dependence-in-depth is good in the cases of the imagined accident scenarios, in the Fukushima case, the reactor operating pump was failed. So, the emergency coolant was not worked at that time. The site operator couldn't follow the manual.

- The leak valve opening: It could remove the hydrogen gas of the reactor and related equipment in the containment building. Once the hydrogen gas was leaked out, the hydrogen explosion did not happen. The operator knew this fact of prohibiting the explosion with the hydrogen leak at that time. However, he was afraid of the legal punishment of hazard radioactive material leak to environment, which could be moved out with the hydrogen gas simultaneously. According to the report, the operator had spent the precious time to seek the prime minister to take the permission of valve-opening. Eventually, the golden time passed and the containment building exploded.

As this Fukushima case, the human couldn't control the improvised situation, because the situation was changed very quickly. The operator couldn't make any action, if the situation is different from the state that indicates in the manual. 


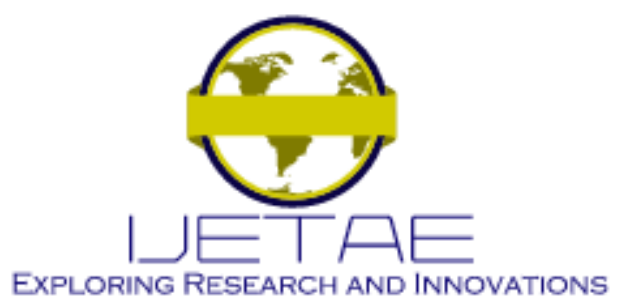

International Journal of Emerging Technology and Advanced Engineering

Website: www.ijetae.com (E-ISSN 2250-2459, Scopus Indexed, ISO 9001:2008 Certified Journal, Volume 11, Issue 10, October 2021)

So, if there was no containment building like the Chernobyl, the hydrogen explosion wouldn't happen in Fukushima. Therefore, the multiple barrier is very doubtful to keep the best way of the nuclear safety system. In fact, this kind of safety system needs very high construct cost. This expensive safety system could be reconsidered for the better NPP where the new kind of the safety system should be designed. In the respect of the situation, the AI-based algorithm could substitute of the human decision-making especially in the severe accident state. There are some RL related papers for the industrial applications. Wang et al. studied for the multi-agent reinforcement learning model in website environment [2]. Moradabadi and Meybodi studied for the Continuous Action set Learning Automata (CALA) [3]. In addition, Niv and Langdon showed the computational theory of reward optimization [4].

\section{METHODOLOGY}

\section{A. Nuclear safety with redundancy concept}

The redundancy method of constructing the safety systems in the NPPs has been very successful in the last six decades where the nuclear fuel is surrounded by several designed protecting equipment including radiation shielding.

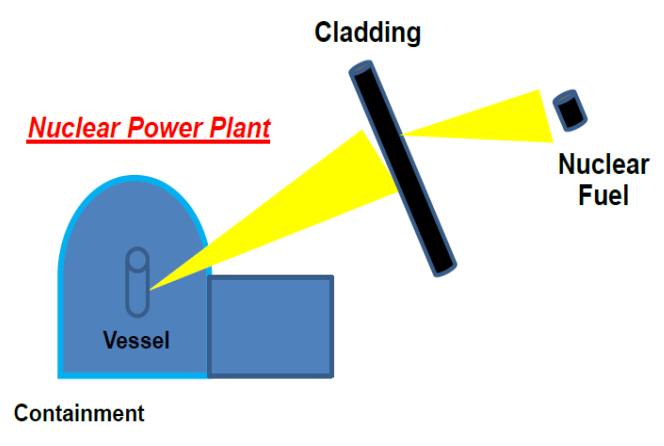

Fig. 1 Typical feature of NPPs.

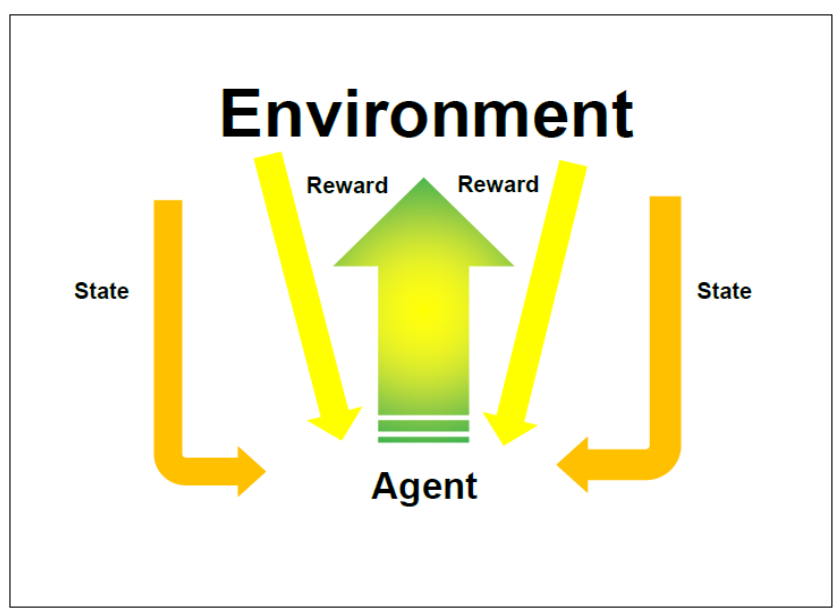

Fig. 2 Configuration of Reinforcement learning (RL).

Until now, the integrity of the NPPs for safety has been done over 16,000 cumulative plant operation years, which is an important matter of the safety analysis where the probability is used of the analysis quantifications [5]. That is to say, as the time goes on, the accident probability could decrease. Hence, the reliability of the reactor would increase. According to a report [6], the redundancy concept can reduce the risk of the plant failure like the aircraft, computer, or so on. There are several graphs in which the more the component is attached, the more the reliability increase in this paper. So, the multiple placed redundancy system can enhance of the component safety. However, a criticism could be existed that the fewer safety systems are effective in the multiple safety actions [7].

In the basic idea of the nuclear systems, the redundancy logic can clearly increase the reliability in the safety assessment and really be effective to control the potential accident. Double or triple components are much more decreasing the possible risk comparing to the single system. Since only one equipment can fail the operation due to the unexpected situations, the compensating system could wisely substitute the failed system. By the way, in the case of the multiple safety systems, it is not easy to mention clearly the anticipated results. 


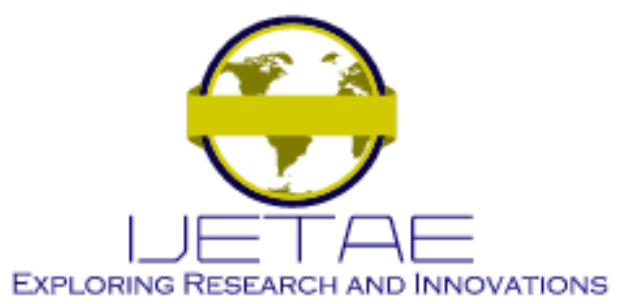

International Journal of Emerging Technology and Advanced Engineering

Website: www.ijetae.com (E-ISSN 2250-2459, Scopus Indexed, ISO 9001:2008 Certified Journal, Volume 11, Issue 10, October 2021)

The operator's behaviour could be affected by the psychological condition. Human possibly can make a mistake in the decision making, especially in the very urgent situation. For example, the operator couldn't open the ventilation value in order to remove the hydrogen gas in the Fukushima nuclear accident. Eventually, the hydrogen explosion happened and the containment collapsed with reactor vessel broken.

\section{B. Skepticism of the nuclear redundancy concept}

The nuclear redundancy is shown in Table 1 [8] in which eight steps are considered. That is, from the nuclear fuel to operation pump, the multiple barrier concept is described. For the case of the Chernobyl, there is no containment building. Hence, lots of hazard radioactive material had dispersed to the environment at that time. By the way, in the case of the Fukushima, the containment building blocks the removing of the hydrogen gases. This resulted to the crucial nuclear disaster in the history of nuclear industry. So, the redundancy system could provoke the unexpected results, which are regarded as the complex nonlinear phenomena.

It is reasonable to suggest non-redundant safety system where the AI-based could be substituted. For example, if the last stage of the multiple barrier in Table 1 failed, the nuclear safety system could go to the critical disaster. So, instead of the multiple safety systems, well-controllable few safety systems could be much more effective in the nuclear accident situations. Therefore, the AI-equipped system can control the emergent situation where the reactor building could be in danger.

\section{Skepticism of the nuclear redundancy concept}

The redundancy system is analysed in this paper where the effectiveness of the nuclear redundancy system is designed with RL. Although the redundancy method in the NPPs has been considered as the safest function. However, all of us have witnessed the system failure in the several accidents as the Fukushima and Chernobyl incidents. So, the non-conventional algorithm is needed to manipulate this kind of problem.
Table I

Multiple Barrier of Typical Nuclear Power Plant

\begin{tabular}{|l|l|}
\hline \multicolumn{1}{|c|}{ Number } & \multicolumn{1}{c|}{ System } \\
\hline 1 & Nuclear fuel grid \\
\hline 2 & Nuclear fuel rod cladding \\
\hline 3 & Reactor pressure vessel \\
\hline 4 & Biological Shield \\
\hline 5 & Containment \\
\hline 6 & Reactor building \\
\hline 7 & Control rods \\
\hline 8 & Circulation pumps \\
\hline
\end{tabular}

Systems thinking is one of non-linear complex algorithms for the applications in the science-technology matters as well as social-humanity tasks where the System dynamics (SD) has been formulated in the computational analysis with the commercialized software as Vensim [9] including some more like Stella [10] or iThink [11]. SD was created by Dr. Jay Forrester in 1960s at MIT. There are several kinds of functions as the feedback thinking [12] where the event flows in the reverse direction that the event sequence is quantified as the designed time steps and directions. This could show a variety of the time flows which could give the reliability or the performance in the interested case. There are some general characteristics of the SD as follows;

- Feedback of event: The event loop could be done as the feedback where the event flows backward. Generalized forward simulation can be reversed and the result could be made differently. In the real situation, the result can affect on the cause of the other event by the feedback.

- Levels of system: The system would be expressed by the cumulative method for the event flows. That is, the RI can be expressed easily by the repeating calculations. Multiple algorithm-based redundancy could be modified by the repeatable algorithm of the SD. 


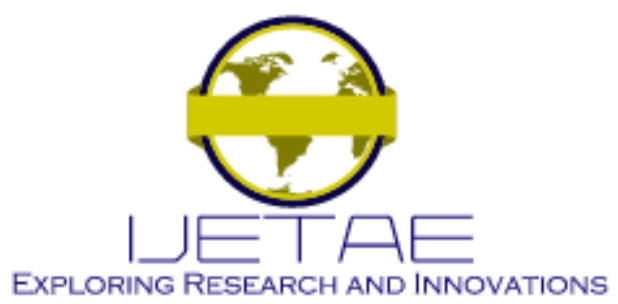

International Journal of Emerging Technology and Advanced Engineering

Website: www.ijetae.com (E-ISSN 2250-2459, Scopus Indexed, ISO 9001:2008 Certified Journal, Volume 11, Issue 10, October 2021)

- Dynamical behaviour: The time flows by the interested directions where the time step could be variable. The shorter time step can increase the calculation sequences. Non-static algorithm can widen the range of the investigation meanings.

There is the transition from the redundancy concept to RL where the characteristics are duplicable and repeatable respectively in Figure 3. There is the comparison between these concepts in Table 2. Figure 4 is the configuration of the RI based management for the anticipated nuclear accident. The cost is much more expensive in the conventional redundancy systems. The construction period also could be longer than that of the RL- based system. In addition, the most important thing of the safety system is that the operator couldn't decide the reasonable decision in the short period at the urgent situation such as the Fukushima case when the operator couldn't open the hydrogen removing value for the ventilations. The operator waited to take the permission from the prime minister who is the person to take the responsibility in the nation. However, if the operator opened the ventilation value, the reactor building would not explode and the radioactive material didn't leak to the atmosphere.

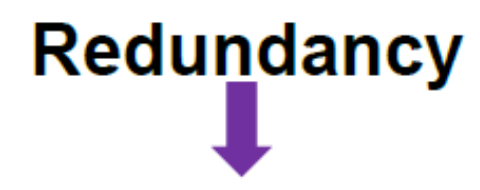

Failure

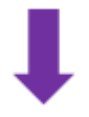

\section{Reinforcement Learning (Logical Repeat)}

Fig. 3 Comparison between redundancy and RL.
Table II

Comparison Between Redundancy And Reinforcement Learning (RL)

\begin{tabular}{|l|l|}
\hline \multicolumn{1}{|c|}{ Redundancy } & \multicolumn{1}{c|}{ Reinforcement learning (RL) } \\
\hline Duplicable & Repeatable \\
\hline Multiple systems & Artificial intelligence (AI) algorithm \\
\hline Expensive & Cheaper after initial development \\
\hline Longer time to construct & Fast and easy to operate \\
\hline
\end{tabular}

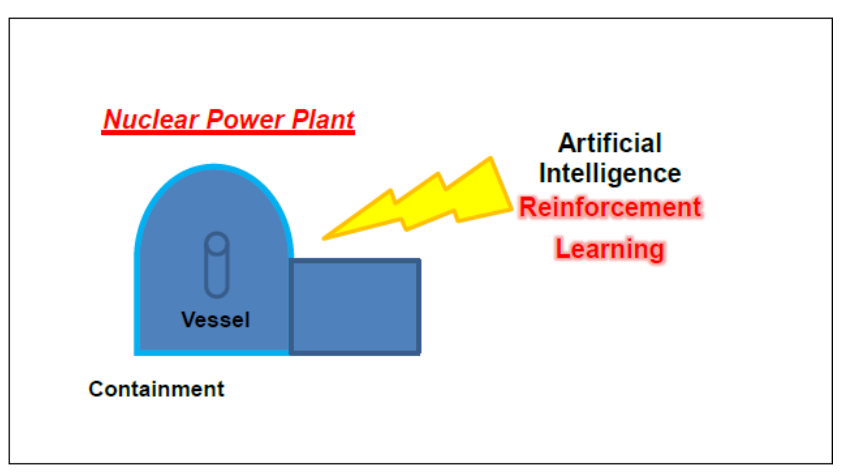

Fig. 4 Management by RL of AI.

Although small amount of the radioactive material could leak to the environment, the damage was extremely negligible considering the real result of the Fukushima disaster.

In this work, the event feedback is designed in the RL where the feedback algorithm gives a kind of learning logic in the AI. In the modelling of the paper, Figure 5 shows the diagrams for the event flows where redundancy, RL, and redundancy with RL are seen. The Vensim code systems is used for the modelling [9].

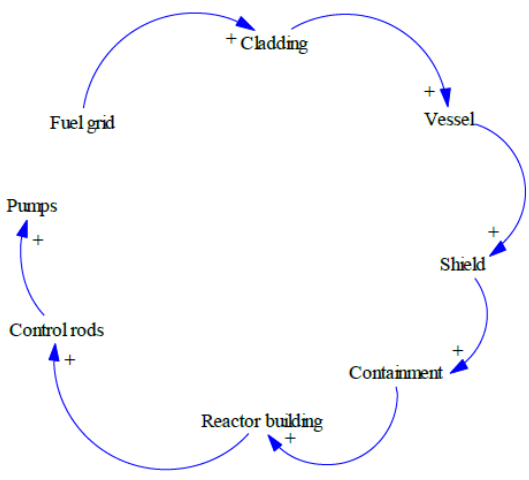

(a) 


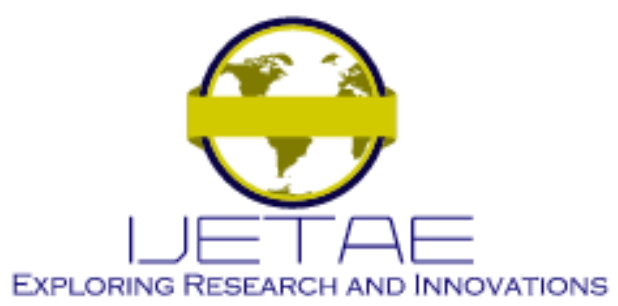

International Journal of Emerging Technology and Advanced Engineering

Website: www.ijetae.com (E-ISSN 2250-2459, Scopus Indexed, ISO 9001:2008 Certified Journal, Volume 11, Issue 10, October 2021)

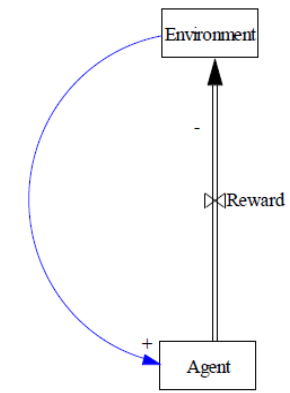

(b)

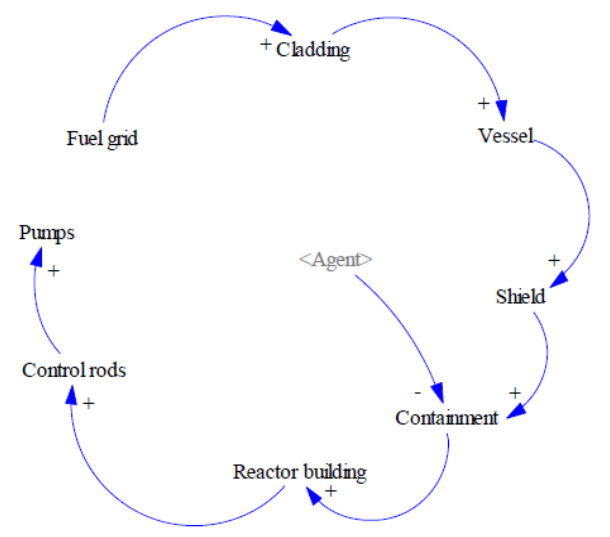

(c)

Fig. 5 Diagram for event flows (a) redundancy, (b) RL, and (c) redundancy with $R L$.

The arrow line shows the event flow with plus sign and minus sign. These present the addition or multiplication for plus sign and the subtraction or dividing for minus sing respectively. In Figure 5 (b), there is a relationship between Environment and Agent. The reward flows from Agent to Environment, although the Environment flows to the Agent. This is a feedback tool in the Vensim code, which expresses the RL. Then, Figure 5 (c) makes the redundancy incorporated with the RL. Each value has made by several calculations which are in Table 3 where the author judgements are reflected. The function is written as IFTHEN-ELSE form. That is [9],

$$
\text { If Then Else (A, B, C) }
$$

If the condition is $\mathrm{A}$, the value is $\mathrm{B}$. Otherwise it is $\mathrm{C}$. For example, in Fuel grid of Table 3, if the generated random number between 0.0 and 1.0 is lower than 0.5 , it is 0.0. Otherwise, it is 1.0. The others are similar to the Fuel grid case.
Especially, the Agent is made by the accumulations of repeated calculation of composed variables as Reward and Environment. This is one of particular characteristics in SD in which the values are added as time goes on. That is, the repeated calculations are analogized as the RL. It is meaningful that the RL could be expressed by the repeated actions such as the SD calculation in this study. Therefore, the RL simulations are successfully accomplished by the SD logic in which the Vensim software is used. In addition, the dynamical quantifications could show the reliability of the designed system where the severe situation like the nuclear accident is informed to the operator. So, the safety system in the NPPs could show the enhanced assessments.

Table III

Values of Multiple Barrier

\begin{tabular}{|l|l|}
\hline \multicolumn{1}{|c|}{ System } & \multicolumn{1}{c|}{ Value } \\
\hline Fuel grid & if then else(random $010<0.5,0,1)$ \\
\hline Cladding & $\begin{array}{l}\text { Fuel grid + if then else(random } 010<0.3,0,1) \\
* \text { Fuel grid }\end{array}$ \\
\hline Vessel & $\begin{array}{l}\text { Cladding+ if then else }(\text { random } 010<0.7,0,1) \\
* \text { Cladding }\end{array}$ \\
\hline Shield & if then else(random $01(0<0.5,0,1) *$ Vessel \\
\hline Agent & if then else(random $010<0.5,0,1)+$ Reward + Environment \\
\hline Containment & (if then else(random $010<0.2,0,1) *$ Shield) / Agent \\
\hline Reactor building & if then else(random $010<0.6,0,1) *$ Containment \\
\hline Control rods & if then else $($ random $01(0<0.5,0,1) *$ Reactor building \\
\hline Pumps & if then else(random $010<0.5,0,1) *$ Control rods \\
\hline
\end{tabular}

D. Comparisons between SD and traditional approach

The nonlinear algorithm like SD has the particular characteristics such as the cases of the fuzzy set and neural networking [12]. The dynamical algorithm with feedback sequence could give the very tractable operations in the event expressions. The expectations of the expert in the modeling have many uncertainties on the conventional probabilistic risk analysis (PRA) in which the statistical methods are utilized as mean and variance values [13]. However, in SD, it is shown that the future could be related to the past as well as the present by the designed modeling algorithm. Furthermore, the statistical expression with mean and variance values could be presented in the SD. Basically, the time connectivity between future and past can increase the reliability in the dynamical assessment, because it is reasonable to consider any event that effects on any time of the event. 


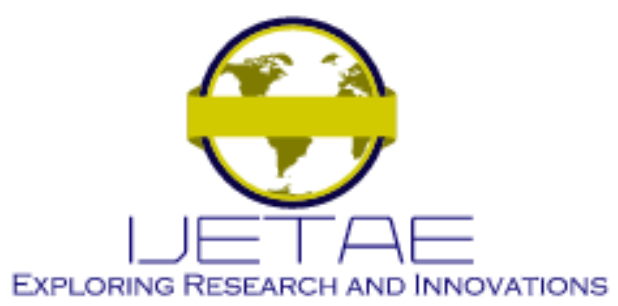

International Journal of Emerging Technology and Advanced Engineering Website: www.ijetae.com (E-ISSN 2250-2459, Scopus Indexed, ISO 9001:2008 Certified Journal, Volume 11, Issue 10, October 2021)

So, the operator can manipulate the time of event scenario by the designed modeling. There is the table for the comparisons between SD and PRA in Table 4. In SD, the event values are produced by the random number and its applications. There are several particular graphics as the arrows and boxes which express the feedback, level, causal loop and so on. This method could be applicable in many industries.

\section{RESULTS}

The Agent expresses the RL as the quantification in Figure 6. Figure 7 shows the results of the simulations where the Agent could reduce the accident possibility of the event. In these graphs, $\mathrm{Y}$-axis means the relative value which shows the quantity of the accident possibility.

Table IV

Comparisons between SD and PRA

\begin{tabular}{|l|l|l|}
\hline \multicolumn{1}{|c|}{ Content } & \multicolumn{1}{c|}{ SD } & \multicolumn{1}{c|}{ PRA } \\
\hline Theory & Random numbers and applications & Probability \\
\hline Graphics & Arrows and boxes & Event tree, Fault tree \\
\hline Quantifications & Numeric values & Numeric values \\
\hline Operators & Feedback, Level, Causes loop, etc. & OR gate, AND gate, etc. \\
\hline Codes & Vensim, Stella, iThink, etc. & $\begin{array}{l}\text { SAPHIRE, RiskSpectrum, } \\
\text { KIRAP, etc. }\end{array}$ \\
\hline Applications & $\begin{array}{l}\text { Risk analysis, Managements, Scientific } \\
\text { assessment, etc. }\end{array}$ & Risk analysis, etc. \\
\hline AI application & Possible & Possible \\
\hline
\end{tabular}

Agent

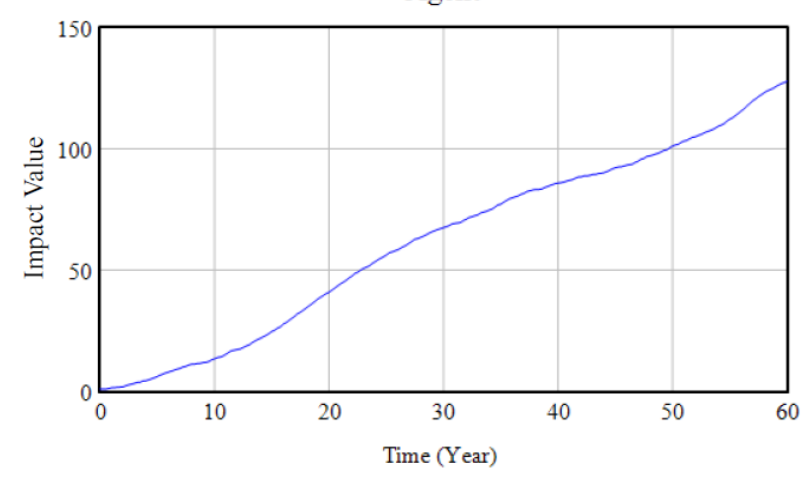

Fig. 6 Agent of RL.

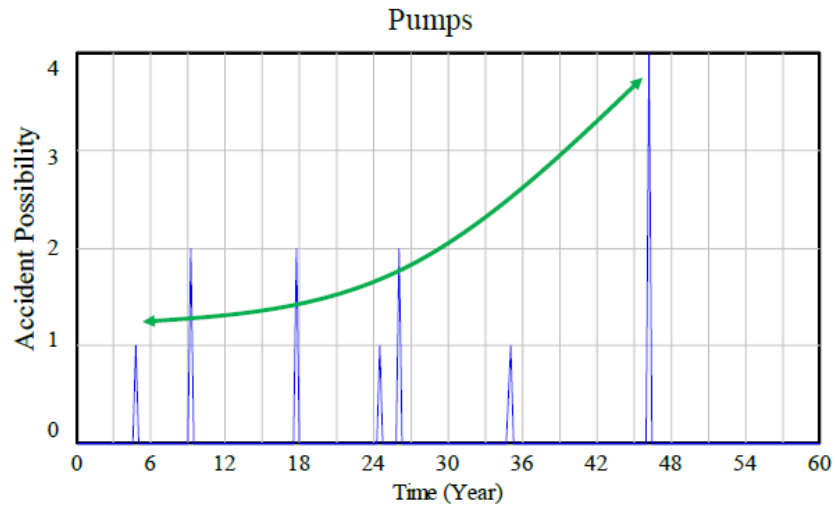

Pumps : Current

(a)

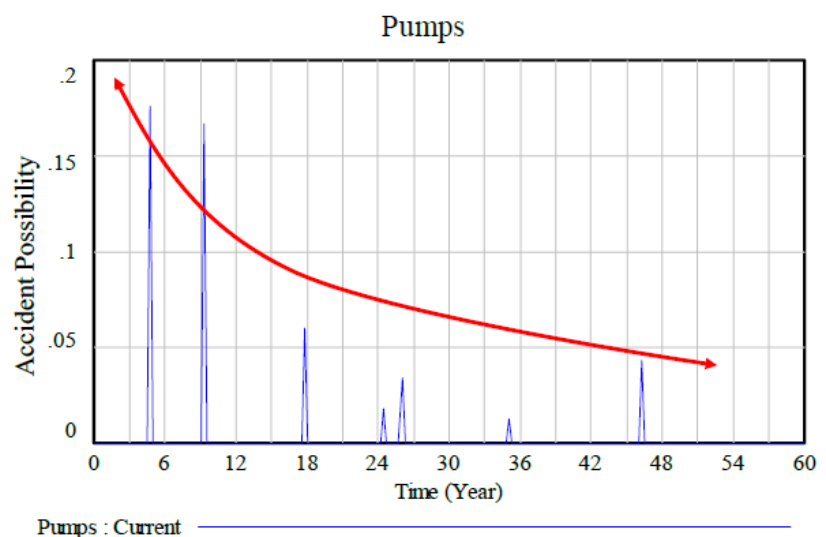

(b)

Fig. 7 Comparison between Pumps (a) without Agent and (b) with Agent.

That is, the higher value means the much more instable state of the pump where the relative comparisons of values are shown without any dimensions. So, the comparative considerations are described in these dynamical sequences in the graphs. The highest values are 4.0 in $46.25^{\text {th }}$ year in which the values are increasing gradually. Otherwise, the values in the case with Agent gradually decrease in the Figure 7 (b). The highest value is near initial stage, which means the operation in NPPs is comparatively unstable. In the Figures 7 (a) and (b), the former value is higher than the later one where the AI based controller is lower than the other one. So, the RL algorithm is expressed by the Agent in this modelling, which is the most important factor in the AI base operation in NPPs. 


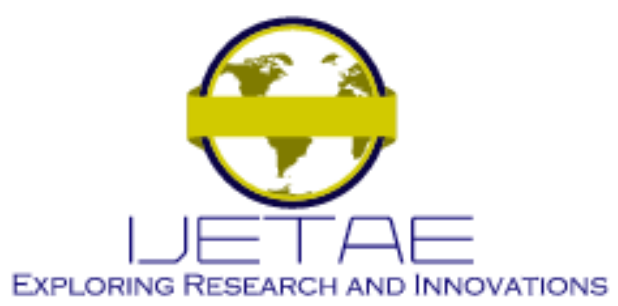

International Journal of Emerging Technology and Advanced Engineering

Website: www.ijetae.com (E-ISSN 2250-2459, Scopus Indexed, ISO 9001:2008 Certified Journal, Volume 11, Issue 10, October 2021)

\section{CONCLUSIONS}

It is investigated for $\mathrm{AI}$ as the RL in the application of the nuclear safety analysis where there SD is used for the mathematical quantification. The non-linear complex algorithm could solve the weakness of redundancy characteristics, even though it has been considered as the best method to strengthen the safety in the NPPs. However, there have been three cases of the redundancy safety failure which had produced very enormous damages to the environment and society. So, the new kind of the strategy of RL could be considered of the solution. There are some findings in this study as follows,

- The AI-based RL for NPP in South Korea is applied.

- The dynamical non-linear complex algorithm is investigated.

- Systems thinking is modelled as the SD.

- The advanced modelling could enhance the reliability of the NPPs.

The SD modelling has the dynamical quantification tool for the designed modelling. Especially, in the study, RL of AI is incorporated with dynamical quantifications which are described by the graphical figures. So, the SD method could give the easy expressions of the dynamical quantifications without several restrictions like the probability function in the conventional approaches.

The high quality of the NPP safety in South Korea needs to keep the integrity of the operations in which past historic nuclear disaster should be revaluated. The redundancy needs to be modified. The paradox of the redundancy concept is discussed, in which although the multiple barrier concept seems to be effective, the operator couldn't make the decision in the shorter time because it is nearly impossible to take the best solution in the very urgent situation. The psychological situation could disturb the operator not to do the right way. So, the AI-based algorithm is one of the best solutions in NPPs operations.

This kind of the RL algorithm can be applied to the educational study. Even the transportation system could be applied in the economic and safety enhancement. The possibility of the human error-based traffic accident could be reduced in which the computational algorithm could be used for the traffic control systems. The complex nonlinear algorithm can improve the integrity of the industrial system. If the AI system of the designed algorithm in this paper is applied to the robotics, the robot worker in the plant site could be used where the highly dangerous environment prohibit human to make the job.
In the market of the robotics, the importance of AI has been increased, because the wise and effective operations of the robotics would be done by the robot intelligence. In the future, the highly intelligent robot would substitute the humans with the well-trained systems. In the other word, the limitation of the human cognitions has approached to the end of the performance by the classical workers. So, it is unavoidable to make use of the machines to control the industrial facilities, especially for the complex systems like the NPPs where the dangerous situation could be done within a short period.

\section{REFERENCES}

[1] Korjus, K., Kuzovkin, I., Tampuu, A., \& Pungas, T. (2014). Artificial General Intelligence that plays Atari video games: How did DeepMind do it? ROBOTS Association," Préverenges, Switzerland. http://robohub.org/artificial-general-intelligence-that plays-atari-video-games-how-did-deepmind-do-it/

[2] Wang, H., Wang, X., Hu, X., Zhang, X., \& Gu, M. (2016). A multiagent reinforcement learning approach to dynamic service composition. Information Sciences, 363, 96-119.

[3] Moradabadi, B., \& Meybodi, M.R. (2016). Link prediction based on temporal similarity metrics using continuous action set learning automata. Physoca A, 460, 361-373.

[4] Niv, Y.A. (2016). Langdon, Reinforcement learning with Marr. Current Opinion in Behavioral Sciences, 11, 67-73.

[5] WNA. (2016). Safety of Nuclear Power Reactors. World nuclear association (WNA), UK. http://www.world-nuclear.org/informationlibrary/safety-and-security/safety-of-plants/safety-of-nuclear-powerreactors.aspx

[6] Sagon, S.D. (2004). The Problem of Redundancy Problem: Why More Nuclear. Security Forces May Produce Less Nuclear Security. Risk Analysis, 24(4), 35-46.

[7] The deproliferator. (2009). When more is less: "Redundancy" may actually reduce nuclear security. Blog at WordPress.com. https://scholarsandrogues.com/2009/12/18/when-more-is-lessredundancy-may-actually-reduce-nuclear-security/

[8] ENS. (2016). Safety barrier, European nuclear society (ENS). https://www.euronuclear.org/info/encyclopedia/s/safety-barriers.htm

[9] Ventana systems. (2016). Vensim. Ventana systems, Inc., Harvard, USA. http://vensim.com/

[10] Isee systems. (2018a). Stella architect. isee systems, Inc., Lebanon, USA. http://www.iseesystems.com/softwares/Stella-iThink.aspx

[11] Isee systems. (2018b). iThink. isee systems, Inc., Lebanon, USA. http://www.iseesystems.com/softwares/Stella-iThink.aspx

[12] SDS. (2021). WHAT IS SYSTEM DYNAMICS? System Dynamics Society (SDS), Albany, USA. http://www.systemdynamics.org

[13] US NRC. (2016). Probabilistic Risk Assessment (PRA), U.S. Nuclear Regulatory Commission (US NRC), Washington, DC, USA. https://www.nrc.gov/about-nrc/regulatory/risk-informed/pra.html 